\title{
GUARDA COMPARTILHADA DE ANIMAIS DOMÉSTICOS
}

Bruno Gabriel Dassie Baptista, José Vitor de Araújo Biagi, Michelli Gomes Durante

Universidade do Oeste Paulista - UNOESTE, Curso de Direito, Presidente Prudente/SP, E-mail: brunodassie@hotmail.com, vitoraraujo 3@hotmail.com, michelli1290@hotmail.com.

\section{RESUMO}

O seguinte trabalho, por meio de apreciações, as decisões judiciais e aspectos científicos, tem por finalidade trazer, de modo objetivo as reflexões e posicionamento do ordenamento jurídico brasileiro sobre o tema dos animais de estimação envolvidos em disputas de guarda no processo de divórcio. Desse modo, aborda a lei brasileira sobre guarda, aos casos envolvendo animais de estimação, em razão da forma de norma especifica. A pesquisa retrata a tarefa do magistrado e tribunal que se posicionarem nos casos em juízo e proporciona requisitos a ser observado para determinação da lide, com vistas ao bem estar do interesse do animal. Na disputa judicial pelos animais é legal a concessão da guarda e direito de visita aos cônjuges - tutores, e a imposição de prestação de alimentos.

Palavras-Chave: Guarda compartilhada, Animais domésticos, Lide.

\section{SHARED HOUSEHOLD GUARD}

\begin{abstract}
The following work, through judgments, judgments and scientific aspects, aims to objectively bring the reflections and positioning of the Brazilian legal system on the subject of pets involved in disputes of custody in the divorce process. Thus, it addresses the Brazilian law on custody, to cases involving pets, by reason of the form of specific rule. The research portrays the task of the magistrate and court that position themselves in the cases in court and provides requirements to be observed to determine the lide, with a view to the welfare of the interest of the animal. In the judicial contest for the animals it is legal to grant custody and visitation rights to the spouses tutors, and the imposition of maintenance.
\end{abstract}

Keywords: Shared guard, Pets, Handle 


\section{INTRODUÇÃO}

Nos tempos atuais, o número de famílias com animais de estimação tem aumentado significativamente, em muitos casos os animais domésticos deixaram os quintais e passaram a coabitar os interiores das casas juntamente com seus donos. Em 2013, o Instituto Brasileiro de Geografia e Estatística (IBGE) divulgou uma Pesquisa Nacional de Saúde (PNS) a qual demonstra que cerca de quarenta e quatro vírgula três por cento $(44,3 \%)$ dos domicílios do Brasil possuem pelo menos um cachorro. Já os gatos estão presentes em pelo menos dezessete vírgula sete por cento $(17,7 \%)$ dos domicílios brasileiros.

Destarte, em virtude desses grandes números de animais presentes nas famílias, empresas têm cada vez mais se especializado no cuidado da saúde, estética e bem estar dos animais. Atualmente existe um nicho muito grande neste mercado que vai desde salão para cuidar da estética até creche para cuidar dos animais.

Com a mudança dos hábitos das famílias, evidenciando a presença de animais de estimação, verifica-se que os pequenos animais deixaram de fazer parte apenas do quintal e passam a ter uma relação financeira e afetiva com seus donos.

No ramo das ciências jurídicas, não é diferente do mundo moderno e globalizado, conforme acontecem mutações nas relações humanas, existem também modificações no mundo jurídico, onde os animais deixaram de ser simplesmente semoventes e passam a pertencer aos seus familiares, gerando obrigações e deveres para seus donos, inspirando, assim, o presente trabalho que tem como objetivo discorrer do tema de guarda compartilhada de animais domésticos.

\section{MÉTODO}

O método utilizado no presente trabalho é pesquisa a legislação, decisões judiciais, bem como, pesquisas realizadas em sites de notícias de âmbito nacional. Por se tratar de um tema ainda pouco debatido, não foram utilizados dados coletados em livro ou doutrinas,.

\section{O CONCEITO JURÍDICO DE ANIMAIS}

No direito brasileiro, especialmente no Código Civil Brasileiro vigente, existem duas classificações jurídicas que são as pessoas e as coisas.

Para Júlio César Ballerini Silva (2017), no artigo "Novas questões jurídicas a respeito de animais de estimação", traz o seguinte conceito sobre animais:

"Pela tradição do direito civil herdada do CC/1.916, animais são bens semoventes, parte do patrimônio de seu titular, o que, numa visão fria, longe da concretude, foi mantido pelo CC atual (entendendo-se por patrimônio a noção de Pontes de Miranda de acordo com a qual esse seria um conjunto de posições jurídicas ativas e passivas, atinentes a um dado titular, sendo passíveis de avaliação econômica e consequente expressão monetária)."

Assim, os animais são classificados como coisa, previsto no artigo 82 do Código Civil, que no seu caput diz "Art. 82. São móveis os bens suscetíveis de movimento próprio, ou de remoção por força alheia, sem alteração da substância ou da destinação econômico-social".

Pois bem, existe em trâmite no Senado Federal da República Federativa do Brasil, o projeto do senador Antonio Anastasia, do Partido Social Democracia Brasileira, do Estado de Minas Gerais (PSDB-MG), que pretende trazer uma nova natureza jurídica para os animais, que deixariam de ser tratados pelo Código Civil Brasileiro como coisas ou bens móveis. 
Para Anastasia, a justificativa para o projeto é a seguinte:

"Alguns países europeus avançaram em sua legislação e já alteraram os seus Códigos, fazendo constar expressamente que os animais não são coisas ou objetos, embora regidos, caso não haja lei específica, pelas regras atinentes aos bens móveis. Isso representa um avanço que pode redundar no reconhecimento de que os animais, ainda que não sejam reconhecidos como pessoas naturais, não são objetos ou coisas".

\section{RELAÇÃO AFETIVA ENTRE ANIMAIS DOMÉSTICOS E PESSOAS}

Conforme ressaltado anteriormente, a relação entre seres humanos nos dias atuais é muito diferente do passado, quando estes eram usados para a proteção do patrimônio, e muitas vezes até para o pastoreio de outros. Os animais faziam suas refeições com sobras do que seus donos comiam, banho era apenas para higiene. Atualmente, os animais fazem parte como um ente querido pela família, tem suas próprias comidas, suas próprias roupas, camas, e ainda, o banho virou além de higiene, serve para deixá-los ainda mais bonitos.

Alguns livros e até mesmo filmes, como o famoso filme "Marley e Eu", relata as relações entre humanos e animais. Mas o que mudou não foi só a forma de cuidar dos animais, mas as relações afetivas, existindo estudos que comprovam o bem que faz se relacionar com esses animais. Os animais não podem mais simplesmente serem tratados como coisas, pois existe um valor sentimental, uma verdadeira amizade entre animais e seres humanos, sendo praticamente impossível estipular um valor econômico e financeiro, característica própria das coisas.

Em seu trabalho, "Relações entre humanos e animais de estimação: pela defesa de um olhar sociológico", autora Kênia Mara Gaedtke, afirma: "O que se pode observar é que as transformações ocorridas na forma como se dá a relação dos humanos com animais de estimação (principalmente cães e gatos, mas também outros) são um reflexo das transformações ocorridas na própria sociedade humana."

Assim, o vinculo entre animais e humanos vai além de uma relação entre animais e pessoas, é criada uma amizade. Existem diversas pesquisas que demonstram os benefícios desta amizade, em algumas cidades cães são usados como terapeutas no tratamento de crianças, como caso de uma escola na Cidade de Campo Grande, Capital do Estado de Mato Grosso do Sul, onde cães são usados no tratamento de crianças portadoras de autismo.

Os animais acabam chegando de diversas maneiras às famílias, seja por meio de compras, doações, adoção e heranças.

Situação que vem apresentando demandas é a que ocorre quando os animais são adotados por casais e os mesmos se separam, como fica essa relação jurídica? Este é o tema do próximo item.

\section{O DIVÓRCIO E A GUARDA COMPARTILHADA DE ANIMAIS}

Por envolver bens e sentimentos, o Divórcio é algo que assola a sociedade desde os primórdios até os dias atuais. Em diversos momentos da história, o divórcio era tido como algo escandaloso e marginalizado pela sociedade. Antes da emenda constitucional n. 66 , o caminho até o divórcio era árduo, que passaria por separação judicial até a finalmente concretizar a extinção do vínculo conjugal. Com advento da Lei $n$. o 11.441, de 04 de janeiro de 2007, aconteceram flexibilizações no direito sucessório e de família, podendo o divórcio ler lavrado até mesmo extrajudicialmente.

Quando tratamos da divisão de bens imóveis numa separação de casal, temos a possibilidade possível de resolução, pois existem pessoas dotadas de conhecimentos técnicos e jurídicos para fazer a partilha dos bens. Quando se trata de filhos, temos sentimentos envolvidos, sendo a solução para o conflito bem mais difícil. 
Agora quando se trata de animais, fica complicado para o direito solucionar o conflito. A inovação é a guarda compartilhada de animais, que já foi alvo de sentença em vários processos, que assim como acontecem com os filhos, os animais também são alvos de terem seus cuidados e obrigações resolvidos em uma sentença judicial.

Recentemente, o Instituto Brasileiro de Direito de Família IBDFAM, noticiou a sentença dada pela Segunda Vara de Família e Sucessões de Jacareí, interior de são Paulo, por decisão do juiz de direito, Doutor Fernando Henrique Pinto, a guarda de um cachorro foi compartilhada por casal que dissolveu seu casamento, em sua sentença o juiz afirmou que por se tratar de um ser vivo a sentença foi baseada no que acontece com os incapazes.

Existe atualmente na Câmara dos Deputados, o projeto de lei 105\2011, é de autoria do Marco Aurélio Ubiali, do Partido Socialista Brasileiro (PSB) do Estado de São Paulo, dispõe "sobre a guarda dos animais de estimação nos casos de dissolução litigiosa da sociedade e do vínculo conjugal entre seus possuidores", que será tema do próximo capítulo.

De autoria do deputado Ricardo Tripoli do Partido da Social Democracia Brasileira de São Paulo (PSDB/SP), o projeto de lei já aprovado pela Câmara dos Deputados n.o 1365/2015, que trata sobre "a guarda dos animais de estimação nos casos de dissolução litigiosa da sociedade e do vínculo conjugal entre seus possuidores, e dá outras providência". O deputado afirma:

"Os animais não podem ser mais tratados como objetos em caso de separação conjugal, na medida em que são tutelados pelo Estado. Devem ser estipulados critérios objetivos em que se deve fundamentar o Juiz ao decidir sobre a guarda, tais como cônjuge que costuma levá-los ao veterinário ou para passear - enfim, aquele que efetivamente o assista em todas as suas necessidades básicas."

\section{CONCLUSÃO}

Cada vez mais são notórias as mutações da sociedade que geram impactos em todo o ordenamento jurídico do Brasil e no mundo. Com a globalização, avanço da tecnologia, e também com a vida cada vez mais atribulada as pessoas têm modificados as suas relações e a forma de se relacionar, como é o caso do que ocorreu com os animais de estimação, que ganharam um novo espaço nas famílias.

O judiciário tenta, enquanto não existem leis que acompanham as mudanças sociais, tem se empenhado a dar soluções aos conflitos da sociedade, como por exemplo, o caso do presente estudo, que é a guarda compartilha de animais.

Destarte a todo o apresentado, conclui-se que é importante ressaltar que o Brasil precisa urgentemente de leis que acompanhem os avanços da sociedade, seja nas relações afetivas, bem como, nas relações materiais, para que os aplicadores do direito tenham leis a sua disposição para resolver os conflitos e interesses da sociedade.

\section{REFERÊNCIAS}

http://www.migalhas.com.br/Quentes/17,MI233779,21048-

Justica+de+SP+determina+guarda+alternada+de+animal+de+estimacao - acesso em 13\08\2015 às $13 \mathrm{~h} 33 \mathrm{~min}$

http://g1.globo.com/natureza/noticia/2015/06/brasileiros-tem-52-milhoes-de-caes-e-22-milhoesde-gatos-aponta-ibge.html - acesso em 13\08\2015 às 14h07min

http://www.planalto.gov.br/ccivil_03/leis/2002/L10406compilada.htm - acesso em 13\08\2015 às $14 \mathrm{~h} 29 \mathrm{~min}$ 
http://www2.camara.leg.br/camaranoticias/noticias/DIREITO-E-JUSTICA/522245-PROJETO-PASSAA-CONSIDERAR-ANIMAIS-COMO-BENS-MOVEIS-E-NAO-MAIS-COMO-COISAS.html - acesso em $13 \backslash 08 \backslash 2015$ às $14 \mathrm{~h} 54 \mathrm{~min}$

http://www.camara.gov.br/proposicoesWeb/fichadetramitacao?idProposicao=498437 - acesso em $13 \backslash 08 \backslash 2015$ às $15 \mathrm{~h} 32 \mathrm{~min}$

http://www.planalto.gov.br/ccivil_03/leis/2002/L10406.htm - acesso em 15\08\2015 às 20h43min http://www.academia.edu/14927042/Rela\%C3\%A7\%C3\%B5es_entre_humanos_e_animais_de_es tima\%C3\%A7\%C3\%A3o_pela_defesa_de_um_olhar_sociol\%C3\%B3gico - acesso em 15\08\2015 às $20 \mathrm{~h} 59 \mathrm{~min}$

http://g1.globo.com/mato-grosso-do-sul/noticia/2015/04/caes-ajudam-no-desenvolvimento-decriancas-com-autismo-em-ms.html - acesso em 15\08\2015 às 20h15min

http://noticias.r7.com/domingo-espetacular/lulu-da-pomerania-e-a-raca-da-vez-filhote-custa-apartir-r-3-mil-10072017 - acesso em 15\08\2015 às 21h23min

http://www.planalto.gov.br/ccivil_03/constituicao/emendas/emc/emc66.htm - acesso em $15 \backslash 08 \backslash 2015$ às $21 \mathrm{~h} 23 \mathrm{~min}$

http://www.em.com.br/app/noticia/nacional/2015/08/02/interna_nacional,674422/projeto-delei-muda-status-de-animais-no-codigo-civil.shtml - acesso em 15\08\2015 às 21h59min

http://www.ibdfam.org.br/noticias/5905/Justi\%C3\%A7a+de+SP+determina+guarda+compartilhad a+de+animal+de+estima\%C3\%A7\%C3\%A3o+durante+processo+de+div\%C3\%B3rcio - acesso em $15 \backslash 08 \backslash 2015$ às $21 \mathrm{~h} 17 \mathrm{~min}$

http://www.migalhas.com.br/dePeso/16,MI252345,101048-Novas+questoes+juridicas+ a+respeito+de+animais+de+estimacao - acesso em 15\08\2015 às $21 \mathrm{~h} 55 \mathrm{~min}$ 